\title{
Graphene Oxide Encapsulated Forsterite Scaffolds: Synergistic Influences on Mechanical Properties and Antibacterial Behavior
}

\section{A. Najafinezhad}

Islamic Azad University of Najafabad

\section{H. R. Bakhsheshi-Rad}

Islamic Azad University of Najafabad

\section{A. Saberi}

Islamic Azad University of Najafabad

\section{A. A. Nourbakhsh}

Islamic Azad University of Najafabad

M. Daroonparvar

University of Nevada Reno

Ahmad Ismail

University of Technology Malaysia

\section{Safian Sharif}

University of Technology Malaysia

Seeram RamaKrishna ( $\nabla$ seeram@nus.edu.sg )

National University of Singapore

\section{F. Berto}

Norwegian University of Science and Technology

\section{Research Article}

Keywords: Forsterite/GO scaffolds, Structural characterization, Mechanical properties, Bioactivity, Antibacterial activity, Biocompatibility

Posted Date: March 1st, 2021

DOI: https://doi.org/10.21203/rs.3.rs-239600/v1

License: (c) (1) This work is licensed under a Creative Commons Attribution 4.0 International License. Read Full License 


\section{Abstract}

It is very desirable to have good antibacterial properties and mechanical properties at the same time for bone scaffolds. Graphene oxide (GO) can increase the mechanical properties and antibacterial performance, while forsterite $\left(\mathrm{Mg}_{2} \mathrm{SiO}_{4}\right)$ as the matrix can increase forsterite/GO scaffolds' biological activity for bone tissue engineering. Interconnected porous forsterite scaffolds were developed by space holder processes for bone tissue engineering in this research. The forsterite/GO scaffolds had a porosity of $77-80 \%$. The mechanism of the mechanical strengthening, antibacterial activity, and cellular function of the forsterite/GO scaffold was evaluated. The findings show that the compressive strength of forsterite/1 wt.\% GO scaffold was significantly increased, in comparison to forsterite scaffolds without GO. Validation of the samples' bioactivity was attained by forming a hydroxyapatite layer (HAp) on the forsterite/GO surface within in vitro immersion test. The results of cell viability demonstrated that synthesized forsterite scaffolds with low GO did not show cytotoxicity and enhanced cell proliferation. Antibacterial tests showed that the antibacterial influence of forsterite/GO scaffold was strongly correlated with GO concentration. The scaffold encapsulated with 2wt.\% GO had the highest bacterial inhibition. As results show, the produced forsterite/1wt.\% GO can be an attractive option for bone tissue engineering.

\section{Introduction}

Like calcium phosphate ceramics, bioceramics is a perfect option because of the chemical composition close to the bone. However, there are a lot of weaknesses that need to be addressed ${ }^{1-3}$. Regarding this, a class of active surface bioceramics consisting of bioactive silicates has been considered as proper candidates for hard tissue regeneration ${ }^{4,5}$. In recent years, several researchers in multiple areas have regarded forsterite ( $\mathrm{FST} ; \mathrm{Mg}_{2} \mathrm{SiO}_{4}$ ) as a silicate-based bioceramic due to the wide variety of uses ${ }^{1,6}$. This bioceramic has strong cytocompatibility and mechanical characteristics that are suitable for tissue engineering applications ${ }^{7}$. Forsterite ceramics showed a dramatic increase in fracture toughness $\left(\mathrm{K}_{\mathrm{IC}}=\right.$ 2.4 $\mathrm{MPa} \mathrm{m}^{1 / 2}$ ) in comparison with hydroxyapatite and bioactive glass (BG) for bone implants applications ${ }^{8}$. Therefore, forsterite is an appropriate choice for both high load-bearing and hard tissue regeneration uses ${ }^{9}$. Multiple studies have shown that employing nano-scale materials can dramatically boost their physicochemical characteristics throughout the past. Therefore, in contrast to micron-scale materials' properties, developed nanostructured materials also display a great combination of various biochemical, electrical, and magnetic characteristics ${ }^{10-14}$. The nanostructured materials are suitable for applications in various fields because of the mentioned remarkable and unique properties. The usage of nanostructure forsterite could also greatly boost its characteristics, such as biocompatibility, biodegradation, and so forth ${ }^{15}$. On the other hand, nanostructure bioactive ceramic-based scaffolds in bone repair are limited due to their poor mechanical properties, mostly low toughness, and weak antibacterial activity ${ }^{6}$. Therefore, in the manufacture of these biomaterials, mechanical strengthening of the bioactive scaffold has proven to be a key issue. Ceramic-based scaffolds fracture, as described in the 
Griffith fracture theory, derives from the micro-cracks within ceramics, rather than breaking atomic bonds ${ }^{8,16}$. Micro-cracks throughout ceramic-based scaffolds are continuously widening and interacting during pressure with one another to induce final brittle fracture. Therefore, ceramic-based scaffolds' practical strengths are usually $2-3$ times smaller than their theoretical values ${ }^{17,18}$. Now, most researchers are mostly focused on controlling crack propagation conditions in bioactive ceramic-based scaffolds with the introduction of the second phase that further enhances the mechanical reinforcement of scaffolds ${ }^{19,20}$. Moreover, because of their excellent mechanical properties (strength of approximately 130 $\mathrm{GPa}$ and modulus of around $1 \mathrm{TPa}$ ), two-dimensional nanosheets like $\mathrm{GO}$ as a main element of nanomaterials, are the most favorable second-phase materials for composites and also can facilitate the load transfer from ceramics to graphene nanosheets due to large specific surface area (approximately $2630 \mathrm{~m}^{2} / \mathrm{g}$ ) that enables a high contact area with the matrix. These properties can improve the mechanical properties of graphene/ceramic composites ${ }^{21-25}$. Moreover, GO provides high antibacterial efficiency thanks to its membrane and oxidative stress with oxygen-containing functional groups at its edge and large surface area. As a matter of fact, $G O$ attaches itself to bacterial cells with its small size

and then disrupts and damages the cell membrane, leading to bacterial membrane degradation ${ }^{18,26-28}$. In several cases, the effect of forsterite on microstructure enhancement and the ceramic-based scaffold's mechanical properties are investigated. Although, the impact of $\mathrm{GO}$ on the mechanical properties and

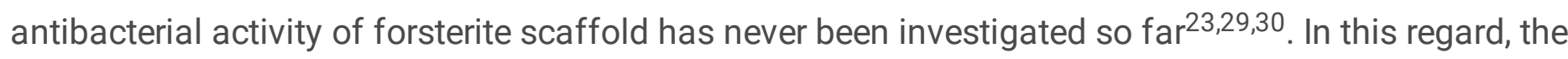
addition of GO in forsterite scaffolds can lead to remarkable antibacterial properties against Grampositive and Gram-negative bacteria ${ }^{31,34}$. In the present paper, dispersing GO nanofiller was constructed and introduced into forsterite scaffolds to increase antibacterial performance and mechanical properties. Three-dimensional porous forsterite/GO nanocomposite scaffolds were fabricated by a combination of semi powder metallurgy (SPM) and space holder methods. The morphology of GO in the forsterite matrix was investigated, and a possible mechanical strength and antibacterial mechanism of forsterite/GO scaffolds were proposed. Moreover, cytocompatibility consisting of cell adhesion, viability, and proliferation was analyzed.

\section{Materials And Methods}

Materials and scaffolds preparation. Primary reagents were magnesium chloride hexahydrate $\left(\mathrm{MgCl}_{2} .6 \mathrm{H}_{2} \mathrm{O} ; 99.9 \%\right.$ purity, Merck, Germany), sodium metasilicate nanohydrate $\left(\mathrm{Na}_{2} \mathrm{SiO}_{3} .9 \mathrm{H}_{2} \mathrm{O} ; 99.9 \%\right.$ pure GR, Shantou Xilong Chemical $\mathrm{Co}$, China) and sodium hydroxide $(\mathrm{NaOH} ; 99.9 \%$ pure, Merck, Germany). These materials were mixed at a molar ratio of 2: $1: 2$, respectively, and afterward poured into zirconia containers and exposed to high ball milling for a brief period (Retsch planetary ball mill type PM 400) ( 10 min). The obtained forsterite powders were then calcined at $1100^{\circ} \mathrm{C}$ and milled under the parameters depicted in Table S1 (presented in supporting information). After that, GO additive with a thickness of 2-5 nm and a surface area of $1000-1300 \mathrm{~m}^{2} / \mathrm{g}$ was prepared using the modified Hummer's method $^{33}$ through chemical oxidation without any further purifying and plunged into ethanol. Therefore, the appropriate weight of forsterite was dissolved in ethanol, and the blended solutions were 
homogenized for a further $1 \mathrm{~h}$ by the magnetic stirrer. Subsequently, the dispersed solutions were combined and sonicated for 30 min before ball milling. The composite was then dried for 1 day in a vacuum drying oven at $100^{\circ} \mathrm{C}$. After that, in order to create forsterite/GO scaffolds, the space holder method was used, during which a suitable weight ratio of forsterite/GO nanopowder to $\mathrm{NaCl}$ particles (as the spacer) with sizes of $450-650 \mu \mathrm{m}$ was chosen. Therefore, the powder was pressed into a cylindrical shape under $110 \mathrm{MPa}(10 \mathrm{~mm}$ diameter $\times 15 \mathrm{~mm}$ height $)$ and then sintered for $4 \mathrm{~h}$ at $1100{ }^{\circ} \mathrm{C}$ at an effective heating rate of $5^{\circ} \mathrm{C} / \mathrm{min}$ as schematically shown in Scheme. 1 . The composites selected for this paper were forsterite/GO composites with $\mathrm{GO}$ contents of $0.5,1.0$, and $2.0 \mathrm{wt} \%$, respectively. To measure the total porosity of the scaffolds, the Archimedes principle has been used is in accordance with following equation.

$$
\text { Total porosity }=1-\frac{\mathrm{Wd}}{\rho\left(\mathrm{Wd}_{\mathrm{d}}-\mathrm{W}_{\mathrm{s}}\right)} \times 100
$$

where, the weight of the specimen in the air is $W_{d}$, the weight of the specimen immersed in water is $W_{S}$, and the true density of the scaffold is $\rho$.

In-vitro bioactivity and antibacterial behavior. Each forsterite/GO scaffold was immersed in $100 \mathrm{~mL}$ of simulated body fluid (SBF) with the chemical composition presented in supporting information (Table S2) at $36.5 \pm 1^{\circ} \mathrm{C}$ for 28 days to investigate the bioactivity assessment. Scaffolds were withdrawn from the SBF containers after that time and cleaned with deionized water, and dried out in the ambient space. Ionic levels of corrosion film were calculated in the SBF solution by the inductive coupled plasma (ICP). During processing, the solution's $\mathrm{pH}$ values were also recorded using a pH meter (PHS-3C, Shanghai Lei Ci Device Works, China).

The antibacterial performance of forsterite/GO specimen in disk diffusion antibiotic sensitivity was evaluated using Staphylococcus aureus (S. aureus, ATCC 12600) and Gram-negative Escherichia coli (E. coli, ATCC 9637) bacteria. The positive control was antibiotic gentamicin (10 $\mathrm{gg} / \mathrm{disc})$. The inhibition area (IA) evaluation was used to evaluate the antibacterial influence of specimens containing various amounts of GO.

In-vitro biocompatibility. The MG63 osteoblast cell line was seeded on sterilized forsterite/GO specimens at a concentration of 2 to $10^{4}$ cells $/ \mathrm{mL}$ and cultured for 3 and 7 days, whereupon the cell-scaffold constructs were stained with DAPI (4',6-diamidino-2-phenylindole, blue fluorescence in live cells) and afterward exposed to fluorescence microscope. On the 3rd and 7th days, ALP activity was measured to determine the effect of GO on the initial osteogenic differentiation of the MG63 cells. In a 24-well plate, cells with a concentration of $10^{4}$ cells $/ \mathrm{ml}$ were placed separately. The cells were remained to grow at 37 ${ }^{\circ} \mathrm{C}$ for different periods according to according to Ref. ${ }^{34}$.

Measurements and characterizations. An Instron-5569 universal machine with a shear rate of 0.5 $\mathrm{mm} / \mathrm{min}$ and a load of $10 \mathrm{kN}$ at ambient temperature was applied to measure the compressive strength of cylindrical scaffolds. Scanning electron microscopy (SEM, JEOL JSM-6380LA) and transmission 
electron microscopy (TEM, Hitachi HT7700, Japan) were performed to evaluate the morphology of the scaffolds. The phase composition of forsterite powder was analyzed using X-ray diffraction analysis (Siemens D5000) using Cu-Ka radiation; in the angle range from $20^{\circ}$ to $75^{\circ}$ at a screening rate of $4 \% \mathrm{~min}$. Also, the Scherer method was used to determine the crystallite size. The chemical compositions of forsterite/GO were analyzed by FTIR analysis using a Thermo-Nicolet 5700 spectrometer. The spectra of samples were recorded at a resolution of $8 \mathrm{~cm}^{-1}$ and a spectral range of 400 to $4000 \mathrm{~cm}^{-1}$. The test outcomes were stated as mean \pm standard deviation (SE), evaluated employing SigmaPlot software with p-value $<0.05\left(^{(}\right), p$-value $\left.<0.01{ }^{(*}\right)$ and $p$-value $\left.<0.001{ }^{(* *}\right)$ to display identified differences between all data.

\section{Results And Discussion}

Microstructural characterization. The XRD spectrum of the calcination powder at $1100{ }^{\circ} \mathrm{C}$ for $2 \mathrm{~h}$ is shown in Fig. 1 a. At $1100{ }^{\circ} \mathrm{C}$, forsterite was synthesized, and no other peaks were observed apart from distinctive forsterite peaks. Additionally, the existence of all sharp peaks in the XRD pattern will indicate the existence of highly crystalline forsterite. The FTIR spectra exhibited the bands of $525 \mathrm{~cm}^{-1}$ and 682 $\mathrm{cm}^{-1}$ is assigned to $\mathrm{Mg}-\mathrm{O}$ and $\mathrm{Si}-\mathrm{O}$ bending modes, even though the band at $815-1000 \mathrm{~cm}^{-1}$ was assigned to $\mathrm{Si}-\mathrm{O}$ bond (Fig. $1 \mathrm{~b}$ ). At $1075 \mathrm{~cm}^{-1}$, the strong band related to $\mathrm{Si}-\mathrm{O}-\mathrm{Si}$ stretching mode was observed $^{7}$. Furthermore, the band of intense at around $3440-3450 \mathrm{~cm}^{-1}$ is attributed to water molecules, meanwhile the intense bands at about $1075 \mathrm{~cm}^{-1}$ is linked with hydroxyl groups was found at Ref ${ }^{1,7}$. The morphology of synthesized forsterite powders is presented in Fig. 1c. As can be seen, the synthesized forsterite powders consist of almost alike particle size nanoparticles in the 50 to $100 \mathrm{~nm}$ range, which presented in agglomeration formed, as presented by FE-SEM image.

The EDS analysis of the fabricated powder is aligned with the XRD outcome; the spectra contained peaks of oxygen, magnesium, and silicon and suggested values of their quantitative ratios that were partially similar to those of forsterite stoichiometry (i.e., 2:1:4 for Mg:Si:O as $\mathrm{Mg}_{2} \mathrm{SiO}_{4}$ ) as exhibited in Fig. $1 \mathrm{~d}$. The particle size and shape of the fabricated FST powder via TEM image presented in the frame. The forsterite particle size distribution is in the 50-100 nm range with a mean particle size of less than 100 $\mathrm{nm}$. Two dominant peaks were observed in the Raman spectra (Fig. 1e) of the neat GNPs, with D and G peaks being detected between 1355 and $1582 \mathrm{~cm}^{-1}$, which is aligned with the vibrational modes of the D-band caused by structural defects and the G-band of the graphic materials ${ }^{35}$. The D peak and $G$ peak are attributed to the stretching of the in-plane $\mathrm{C}-\mathrm{C}$ bond in $\mathrm{GO}$. The attained ID/IG intensity ratio values for graphene oxide are about $0.88^{35-37}$. As presented in Fig. 1f, the XRD pattern of GO powder displays characteristic peaks ${ }^{37}$ at $2 \theta=10.03^{\circ}$, connected to the preferable orientation (001) of GO.

The TEM image showed that the forsterite/GO possesses a spherical shape, which merged and created agglomerate with a mean particle size of almost 80-100 nm (Fig. 2a-e). Although, GO offers a flake-like shape with a thickness of almost 3-5 $\mathrm{nm}$, which is higher than that of neat graphene $(0.355 \mathrm{~nm})$ owing to the oxygenated groups in GO. Moreover, the images show the homogenous distribution of forsterite inside 
the GO sheets with great attachment. The homogeneous dispersion of nanofillers in the matrix, as described in the literature ${ }^{38,39}$, is an important requirement for preparing ceramic-based scaffolds nanocomposites with unique efficiency. The XRD pattern of forsterite, and forsterite/GO scaffold is shown in Fig. 2f. This pattern depicted the typical peaks of forsterite (Standard cards No. 190239) ${ }^{4}$. The patterns were identical since there was no data from the second phase, indicating that $\mathrm{GO}$ and forsterite had no unusual reaction. Moreover, the XRD pattern of forsterite/GO shows that no other phases except forsterite phases have been identified in the scaffold because it is beyond the detection ability of XRD to identify $\mathrm{GO}$ due to its small amounts.

The SEM image of the forsterite and forsterite/GO scaffolds is presented in Fig. 3. Most pores in the framework of porous scaffolds maintained their open porosity on all sections for entire kinds of scaffolds. The SEM micrographs of four scaffold forms, achieving maximum porosity $(\sim 76-80 \%)$ of the scaffolds of around 450-650 $\mu \mathrm{m}$ pore size. As can be observed in a high magnification image, the forsterite particles were spherical with an agglomerate size of 200-250 nm. As shown in Fig. 2a (TEM image), GO was very thin with a few wrinkles. Furthermore, almost all forsterite particles are adsorbed on the GO surface, and a very small number of forsterite particles are located outside the GO support, which means that there is good interaction between forsterite and GO (Fig. 2b). Micropores on the macropores' walls of the forsterite-GO bioceramic have been shown to play a main role in osteoinduction. The 3D structure was already stated to enable the porosity, pore size, and interconnectivity of natural bone to be preferably imitated, escalating cell attachment and proliferation, creating room for new tissue growth and vascularization ${ }^{40}$.

Highly porous scaffolds are required, but these high levels of porosities have great effects on the mechanical properties of scaffolds ${ }^{41}$. Also, adding 0.5 to $2 \mathrm{wt}$.\% GO in the forsterite scaffold has a less significant impact on the porous size of the scaffold. With the increase in $\mathrm{GO}$ amount, a similar pattern was observed concerning interconnected porosity and total porosity. In this regard, it was suggested ${ }^{8}$ that the minimum pore size needed for the growth of the surrounding bone with a blood supply is about 150$100 \mu \mathrm{m}$. Moreover, they indicated which the pores' minimum size that can fill the surrounding bones is so important. From the figure, it was obvious that the pore size and an interconnected pore structure are ideal and proper for the growth of osteoblasts, fast vascularization, and reconstruction of bones. To maintain the scaffold's mechanical stability, fast vascularization is required since it gradually degrades throughout bone reconstruction ${ }^{42,43}$. To allow biomolecules to readily enter and leave the scaffold, an interconnected porous network was therefore required.

Mechanical properties of forsterite/GO scaffolds. Compressive strength (CS) of the forsterite and forsterite/GO scaffolds is shown in Fig. 4a-d. The compressive strength of the forsterite, forsterite/0.5GO, and forsterite/ $1 \mathrm{GO}$, and forsterite/ $2 \mathrm{GO}$ scaffolds was $0.7 \pm 0.05,1.5 \pm 0.12,2.9 \pm 0.15$ and $2.1 \pm 0.12 \mathrm{MPa}$, 
respectively. This trend indicated which forsterite/1GO scaffolds showed more CS than other scaffolds. In comparison to neat forsterite, forsterite composites presented higher CS, which indicates a higher loadbearing capacity after using nanofillers, and a great impact of GO dispersion as a reinforcing phase in the forsterite scaffold matrix on the maintaining mechanical integrity of the scaffold ${ }^{23}$. Regarding this, GO might play a carrier's role and be willing to shift the stress from the scaffold to the GO sheets inside the matrix. Moreover, more compressive strength is obtained by increasing the amount of GO due to its hard nature that increases the compressive strength of the ceramic-based scaffold matrix. Although the mechanical performance can be increased by a further increase of the GO content ( $2 \mathrm{wt} . \%)$, which can be related to GO aggregation, even they are still increased compared to forsterite scaffolds without GO. Thus, it can be concluded that adding GO can significantly enhance the mechanical properties of forsterite scaffolds. Additionally, the excessive addition of GO causes agglomeration, which may partly prevent the composites from densification, and a reduction in density can supply more space for grain size growth. So, the forsterite/1.0wt.\%GO scaffold has optimal compressive strength due to better performance, higher density, and better GO distribution.

It was quite obvious which GO was at the border of the forsterite grains. The high surface area of GO can increase the contact surface with the forsterite matrix. Consequently, the compressive strength of the scaffold is escalated as a result of the bonding strength among GO and the forsterite particles was greatly increased and more energy was required to extract the $G O$ from the forsterite matrix ${ }^{18}$, Fig. 4 e shows the schematic view of enhancement mechanisms related to the morphological evidence, in order to study the toughening mechanisms in further detail. When a crack forms and expands in the forsterite matrix, the load is transferred from the forsterite matrix to the GO because of the elastic modulus difference. The texture of the GO wrinkled surface allows mechanical bonding and load transfer to the matrix. The mechanism of crack deflection is shown in the figure. Due to graphene oxide's extreme surface area, high stress is required to pass the crack; therefore, it causes crack deflection. In fact, GO acts as a barrier and prevents the crack from spreading on the scaffold surface of forsterite/ $1 \mathrm{wt} \% \mathrm{GO}$ Scaffold. Scaffolds containing GO reinforcement need further energy to propagate cracks, which increases the toughness of the scaffold ${ }^{39}$. GO makes the preferential displacement between opposite crack surfaces difficult by reducing the stress required to propagate more cracks. In this respect, once a crack is propagated and clash with GO, the path is blocked, and then the crack path is deflected. This mechanism creates a complicated path for stress release that can increase toughness ${ }^{18,44}$. The improvement of mechanical properties at total nanofiller amounts of $1 \mathrm{wt} . \%$ maybe due to the accumulation of $\mathrm{GO}$ as a reinforcement agent at a great concentration ( $2 \mathrm{wt} . \% \mathrm{GO})$. Therefore, the desired mechanical characteristic was obtained when the optimum amount of $1 \mathrm{wt} . \% \mathrm{GO}$ is encapsulated in the scaffold.

Bioactivity of forsterite/GO scaffolds. In vitro bioactivity was assessed for forsterite/GO scaffolds concerning apatite-forming potential by SBF tests. It was interesting that forsterite scaffolds showed a great increase in mechanical properties and kept optimal bioactivity after adding GO, as can be observed 
in Fig. 5. SEM image demonstrated that a variety of tiny mineral clusters precipitated over the surface of the scaffold during 7 days of exposure to the SBF. As can be seen in the high-magnification image, these clusters are composed of crystallites with a spherical and flat appearance. The results obtained for forsterite/GO scaffolds were similar. According to Fig. 5, HAp formation appeared after 7 days in SBF with normal cauliflower morphology. In addition, apatite film cracks are usually attributed to hydrated layer contraction throughout the drying procedure. Their capacity to trigger apatite generation has been well established in the SBF, mainly due to the strong forsterite reactivity. The origin of the process of this capacity can be described in the following stages: first, through the exchange of $\mathrm{H}^{+}$in the solution, the $\mathrm{Mg}$ and $\mathrm{Si}$ ions are emitted into the surrounding fluid. The degradation of scaffolds leads to the release of $\mathrm{Mg}$, and $\mathrm{Si}$, which is biocompatible (Fig. $6 \mathrm{a}$ ). $\mathrm{Mg}$ being released preferentially relative to $\mathrm{Si}$ ions, which causes a silanol-rich layer $(\mathrm{Si}-\mathrm{OH})$ creation. Secondly, $\mathrm{Ca}^{2+}$ ions in the SBF solution are electrostatically adsorbed on the newly formed layer that is negatively charged because of forming $\mathrm{Si}-\mathrm{OH}^{45}$. The existence of a negative charge on the $\mathrm{Si}-\mathrm{OH}$ group initially interacts with the $\mathrm{Ca}^{2+}$ ions (positively charged) in the physiological media. In interaction with the physiological media, it induces amorphous silicate on the overlayer ${ }^{5}$. This film continues to interact with physiological media until a film containing $\mathrm{Ca}^{2+}$ ions fully covers the scaffold surface ${ }^{46}$. After that, in the direction of the outer layer, the negatively charged $\mathrm{CO}_{3}{ }^{2-}$ or $\mathrm{PO}_{4}{ }^{3-}$ ions are attracted, and the apatite layer grows with increasing soaking time as the ions in the physiological media are absorbed. Consequently, the prediction of forsterite bioceramics' bioactive output appears to be based on silicon as a fundamental element ${ }^{7,47}$. As the findings show, the addition of different GO amounts may not impede the bioactivity of forsterite scaffolds due to the formation of apatite on the scaffold surface.

The key explanation for the changes in $\mathrm{pH}$ was the solubility of forsterite/GO scaffolds. As observed, the $\mathrm{pH}$ curve for forsterite/GO raised dramatically to 7.91 after 5 days of soaking in physiological media (Fig. $6 b$ ). The $\mathrm{Mg}$ and $\mathrm{Si}$ ions of the scaffolds are exchanged with $\mathrm{H}^{+}$or $\mathrm{H}_{3} \mathrm{O}^{+}$to create $\mathrm{Si}-\mathrm{OH}$ on the surface following incubation of the scaffolds in the physiological media. A dense film of calcium phosphate was generated on the scaffold surface after the migration of $\mathrm{Ca}^{2+}$ and $\mathrm{PO}_{4}{ }^{3-}$ to the surface of the scaffolds, lessening the $\mathrm{pH}$ to 7.44 (after 9 days). Crystallization of the amorphous film of Ca-phosphate was then emerged by combining $\mathrm{OH}^{-}$or $\mathrm{CO}_{3}{ }^{2-}$ from the physiological media ${ }^{1,5,47}$. This hydroxyl carbonate apatite layer could bind implants to bone tissue. As reported earlier, the $\mathrm{pH}$ of the leach solution increases because of the preferential dissolution of $\mathrm{Mg}^{2+}$ and $\mathrm{Si}$ ions, which leads to the increase of supersaturation with respect to apatite and therefore helping the deposition of the apatite.

Some findings demonstrate that the biomimetic HAp mineralization of GO encapsulated forsterite scaffold can be accomplished in the physiological media ${ }^{48}$. Wen et al., ${ }^{49}$ for instance, demonstrated a simple biomimeric approach for the development of 3D hierarchical GO-HA nanocomposites by immersing in a modified SBF solution. It is worth noting that the $\mathrm{Ca}^{2+}$ ions are adsorbed by electrostatic interactions with oxygen-active groups on the GO surface in SBF. Then small apatite crystals are created in a brief time. After more nucleation and growth of crystal, adjusting the mineralization period can lead 
to formation of nanoscale and microscale HAp crystals. In addition, oxygen-containing functional groups of GO sheets lead to a more compact apatite layer by providing a great number of nucleation centers and accelerate the the deposition of the apatite, thus the $\mathrm{pH}$ value reduced ${ }^{48}$.

Changes in SBF solution concentrations of $\mathrm{Ca}, \mathrm{Mg}, \mathrm{Si}$, and $\mathrm{P}$ ions following soaking of forsterite/GO scaffolds for different immersion periods are shown in Fig. 6c. It can be observed which an increase of the immersion time reduces the $\mathrm{Ca}$ and $\mathrm{P}$ ions concentration, but there seems to be an opposite pattern for $\mathrm{Mg}$ and $\mathrm{Si}$ ions. $\mathrm{Ca}$ and $\mathrm{P}$ ions are reduced by the deposition of apatite on the scaffold surface caused by the increase of the immersion time. Oppositely, an increase of the immersion time increases the level of $\mathrm{Mg}$ and $\mathrm{Si}$ ions, which can be related to the degradation of the forsterite-based scaffold ${ }^{16}$.

The FTIR spectrum of the forsterite/GO scaffold shows the creation of HAp-related typical peaks, i.e., the well-defined peak at $1070 \mathrm{~cm}^{-1}$ allocated to the $\mathrm{P}-0$ stretching mode and the double peak at 608 and $567 \mathrm{~cm}^{-1}$ of the $\mathrm{P}-\mathrm{O}$ bending mode in HAp as shown in Fig. $6 \mathrm{~d}$. In addition, the creation of hydroxyapatite film accompanied by peaks at 1430 and $870 \mathrm{~cm}^{-1}$ was proved to be connected to the $\mathrm{CO}_{3}{ }^{2-}$. Therefore, the existence of hydroxyapatite on the surface of scaffolds with graphene oxide after immersion in SBF for 7 days showed which this nanofillers did not adversely affect the bioactivity of forsterite/GO. Peaks can be linked to Si-O stretching vibration modes at 832 and $965 \mathrm{~cm}^{-1} 19,50$. Moreover, it was reported that a specific property of bioactive materials, like silicate-based ceramics, is dynamic and time-dependent changes in the surface that occur in contact with them. The bonding interface with bone and soft tissues is provided when a highly reactive HA layer is formed.

Fig. 6e illustrates the XRD spectra of the forsterite/GO scaffold containing various amounts of $\mathrm{GO}$ after exposure in SBF for 28 days. For entire scaffolds and alongside with the distinctive peaks of forsterite, the characteristic peaks of HAp at $2 \theta=26.5^{\circ}, 32^{\circ}$ and, $47^{\circ}$ can be seen, which show forming an HAp phase after 28 days of exposure in $\mathrm{SBF}^{19,50}$. No phases containing magnesium were found on the scaffold surface, which may be due to the low concentration of magnesium in the deposited layer.

Cytocompatibility. As cells can contribute effectively to apatite deposition and new bone tissue development, cell viability, and proliferation in the bone scaffold are required for bone reconstruction ${ }^{51}$. For various period intervals, MG-63 cells were cultured on scaffolds and afterward evaluated by fluorescence staining, ALP staining, and DAPI staining in order to assess cell behavior in forsterite/GO scaffolds in the presence of different amounts of GO. The fluorescence image also shows the results of cell attachment on the forsterite/xGO scaffold after 3 days (Fig. 7a-d). Obviously, the cells attach and spread well all over the whole forsterite-based scaffold except scaffold with a high amount of GO showing that scaffolds with low GO amount have good cytocompatibility. In fact, cells cultured in scaffolds incorporated with $2 \mathrm{GO}$ failed to cell spread and propagated. It shows great cell number reduction in the forsterite/GO scaffold containing large amounts of $\mathrm{GO}$ indicating that extra GO amount adversely affects the cell. According to the results, low amount of GO have an advantageous effect on 
cell attachment while excess $\mathrm{GO}$ has a negative effect ${ }^{23,51,52}$. MTT method was used to evaluate cell viability, and the result showed that forsterite/GO scaffolds with low GO concentration have the least effect on cell viability (Fig. 7e). Regarding this, the toxicity of GO is reduced by its low incorporation in the scaffold, as it may prevent the direct connection of GO that results in cell destruction. Conversely, large amounts of GO (2 wt.\%) in the scaffold causes low cytotoxicity of the scaffold.

Alkaline phosphatase (ALP) is considered the first sign of osteoblast differentiation throughout bone growth owing to enhanced cell differentiation as long as bone cells are generated. ALP activity of forsterite/GO scaffolds after cell incubation is shown in Fig. $7 \mathrm{f}$ for various culture times. Typically, total scaffolds show higher ALP activity than forsterite/2GO over the time course of culture. ALP activity of forsterite and forsterite/GO scaffolds presented significant improvement after 7 days of culture. Thus, forsterite with a low GO amount offers higher ALP activity in comparison to those with higher amounts and may ultimately better support osteoblast differentiation. As a matter of fact, ALP decreases significantly with increasing high GO concentration (2 wt.\%) in forsterite-based scaffolds. The synergistic influence of $\mathrm{GO}$ on cell behavior may be attributable to oxygen-containing functional groups on their surface ${ }^{46}$. According to Munir et al. ${ }^{52}$, the hydroxyl groups in $\mathrm{GO}$ my present sites for cell attachment and proliferation. Similarly, Gao et al. ${ }^{18}$ demonstrated that $\mathrm{GO}$ provides a forum for the creation of a biointerface for cell proliferation and adhesion.

Fig. $\mathbf{7 g}$ shows schematic images to understand better the forsterite/GO scaffold's positive and negative effects on cell-surface interactions with BCs surface. To discuss the synergistic effect of carbon-based nanostructure on cell attachment and proliferation, protein absorption and better cell adsorption are related to wrinkles on the surface of graphene-based material. Gao et al. ${ }^{18}$ also reported similar results which their study confirms the positive effect of graphene-based material surfaces on protein absorption. In addition, the destructive effect of GO (at high doses) has been shown to be due to two reasons: mitochondrial dysfunction is related to the overproduction of ROS. Lee et al. ${ }^{53}$ reported that the graphenebased materials could reduce the mitochondrial membrane potential (MMP). Thus the level of intracellular ROS is enhanced that activates the mitochondria-dependent apoptotic pathway. Moreover, ROS causes DNA damage, both results in reduced cell viability. Several previous studies ${ }^{52,54}$ have confirmed the toxicity of graphene nanomaterials in varying sizes in dispersed solutions. For example, nanosheet graphene is readily taken up and then accumulated in cells with lateral dimensions of $100 \mathrm{~nm}$. Hegab et al. ${ }^{55}$ confirmed the edge-first insertion, penetration, and internalization of graphene microsheets (multilayered, 0.5-10 $\mu \mathrm{m}$ ) into the three cell types' lipid bilayers by Brownian motion and lipid attraction. Very large macrosheets, such as 20-100 micrometers (larger than most cells), may pose a risk, for example, by using a similar "wrapping/ encapsulation" of those bacteria, causing a nutrient deprivation. That being said, given the limited mobility of the sheet, owing to the covalent or electrostatic layers of the substrates, free-floating sheets are impossible. Therefore, the risk of high-risk penetration and cell adsorption of nanoparticles or large film wrapping (e.g., bulk GO) of host cells should indeed be quite low $^{52,55}$. According to the mentioned results, the encapsulation of $1 \mathrm{wt} . \% \mathrm{GO}$ to forsterite scaffolds could 
escalate biocompatibility base on the cell viability and attachment, ALP activity, and apatite precipitation, which can be very important for the clinical usage of forsterite/GO scaffolds.

Antibacterial properties. A qualitative assessment of the antibacterial efficiency of forsterite/GO scaffolds with inhibition area (IA) was carried out for 24 hours (Fig. 8a, b). Forsterite scaffolds do not show antibacterial performance due to the increase in the culture medium's $\mathrm{pH}$ because it has been shown that a change in $\mathrm{pH}$ is contrary to bacterial growth. As shown in the figure, IA was present around all forsterite/GO scaffolds, indicating the antibacterial performance of GO-containing FST scaffolds. Obviously, the forsterite/ $0.5 \mathrm{GO}$ scaffolds showed an IA diameter of $2.8 \pm 0.2 \mathrm{~mm}$; however, the forsterite/2GO scaffolds showed a diameter of $4.9 \pm 0.3 \mathrm{~mm}$ against E.coli bacteria. It was noteworthy which the forsterite/2GO scaffolds had a higher IA diameter than both forsterite/1GO scaffolds and forsterite/0.5GO scaffolds, showing the great impact of $\mathrm{GO}$ on the antibacterial performance of the forsterite-based scaffold (Fig. 8c). An increase of the $\mathrm{GO}$ amount from 0.5 to $2 \mathrm{wt} \%$ greatly increases the inhibition area to $2.7 \pm 0.2 \mathrm{~mm}$ and $4.7 \pm 0.3 \mathrm{~mm}$, because of the higher release content of GO against $S$. aureus bacteria. Several papers ${ }^{52,54,56}$ have shown that $\mathrm{GO}$ sheets might cut bacterial cell wall membranes to prevent them from proliferation and growing, creating oxidative stress that leads to disruption of the membrane. Direct interaction of bacteria with ultra-sharp GO edges contributes to the deterioration of the cell membrane and bacterial breakdown ${ }^{52,54}$. In addition, the $\mathrm{GO}$ sheet represents an attractive bacterial attachment surface area, enabling actual interactions between the scaffold surface and the bacteria membrane. Therefore, the forsterite/GO scaffold kills E.coli bacteria caught on the surface of the scaffold.

The reduction percentage of $S$. aureus and $E$. coli for forsterite/GO scaffolds with different GO concentrations from 0.5 to $2 \mathrm{wt}$ \% are shown in Fig. 8d. The presented graph of forsterite scaffolds did not show any bacterial decrease while, forsterite/GO showed an incredible decrease of bacteria. There is a similar decrease trend for forsterite scaffolds containing 0.5 to 2 wt. $\%$ GO in which $65 \pm 2$ to $90 \pm 2 \%$ of the bacteria are wiped. In general, forsterite/2GO has showed a significantly higher bacterial inhibition compared to other scaffolds, which indicates that incorporation of GO in the scaffold leads to a great impact on antibacterial reduction. Clearly, E. coli with additional cell walls composed of many peptidoglycan layers is more resistant to attack by GO sheet encapsulated forsterite scaffold.

Fig. 8e shows the antibacterial mechanism of forsterite scaffolds containing GO. The encapsulated GO as an antibacterial agent into the scaffolds can causes great antibacterial efficiency. The interaction of forsterite/GO scaffolds with bacteria causes the formation of GO sheets attached to the bacteria and disintegrates them. After that, GO sheets with sharp edges spread into the bacterial cytomembrane, damage the cells physically and inhibit cell growth, because of the action of oxidative stress on the bacteria. The antibacterial action of forsterite/GO scaffolds is at first related to the production of GO and escalated generation of reactive oxygen species (ROS), that damage the bacterial respiratory system and also the penetration of sharp and thin edges of $\mathrm{GO}$, leading to cell membrane integrity destruction. Three significant mechanisms, namely nanoknives, ROS generation and charge transfer, appeared to be 
functional in these situations. We intend to offer putative mechanistic ties for the formation of graphene interfaces through the use of these mechanisms.

\section{Conclusions}

The forsterite/GO scaffolds with various amounts of GO are effectively prepared by semi powder metallurgy coupled with space holder methods to achieve high strength, bioactivity, and strong antibacterial performance. Adding GO to the forsterite scaffold significantly improves the mechanical integrity of the forsterite-based scaffolds. A model was proposed to detect antibacterial activity and cellular interaction with forsterite/GO scaffolds. Forsterite/GO scaffolds with low GO concentrations provide a more suitable surface for adhesion, proliferation, and MG-63 cell growth. Encapsulation of GO in forsterite scaffolds reduces $S$. aureus and $E$. coli bacterial growth, in which the percentage of bacterial reduction increases with increasing GO concentration from 0.5 to $2 \mathrm{wt} . \%$. According to the obtained results, the performance of the incorporation $1 \mathrm{wt} . \% \mathrm{GO}$ into forsterite scaffolds can be a potential strategy to increase mechanical performance and antibacterial properties.

\section{Declarations}

\section{Acknowledgements}

The authors acknowledge the financial support from the University Teknologi Malaysia (UTM) and Norwegian University of Science and Technology for providing the facilities of this research to the present study.

\section{Conflict of interests}

The authors declare that they have no competing/financial conflict of interests.

\section{Author contributions}

H.R. Bakhsheshi-Rad, A. Najafinezhad, A. Saberi; Writing-original draft preparation, methodology, formal analysis and A. F. Ismail, S. Sharif, S. RamaKrishna , F. Berto, : Conceptualization, supervision, review and editing and A.A. Nourbakhsh, M. Daroonparvar: Writing- review and editing

\section{References}

1. Kheradmandfard, M., S.F. Kashani-Bozorg, A.H. Noori-Alfesharaki, A.Z. Kharazi, M. Kheradmandfard and N. Abutalebi, Ultra-fast, highly efficient and green synthesis of bioactive forsterite nanopowder via microwave irradiation. Materials Science and Engineering: C, 2018. 92: 236-244.

2. Lee, D., M. Wufuer, I. Kim, T.H. Choi, B.J. Kim, H.G. Jung, B. Jeon, G. Lee, O.H. Jeon, H. Chang, and D.S. Yoon, Sequential dual-drug delivery of BMP-2 and alendronate from hydroxyapatite-collagen scaffolds for enhanced bone regeneration. Scientific Reports, 2021. 11(1): 746. 
3. Samadian, H., H. Mobasheri, M. Azami and R. Faridi-Majidi, Osteoconductive and electroactive carbon nanofibers/hydroxyapatite nanocomposite tailored for bone tissue engineering: in vitro and in vivo studies. Scientific Reports, 2020. 10(1): 14853.

4. Choudhary, R., A. Chatterjee, S.K. Venkatraman, S. Koppala, J. Abraham and S. Swamiappan, Antibacterial forsterite $\left(\mathrm{Mg}_{2} \mathrm{SiO}_{4}\right)$ scaffold: A promising bioceramic for load bearing applications. Bioactive Materials, 2018. 3(3): 218-224.

5. Diba, M., O.-M. Goudouri, F. Tapia and A.R. Boccaccini, Magnesium-containing bioactive polycrystalline silicate-based ceramics and glass-ceramics for biomedical applications. Current Opinion in Solid State and Materials Science, 2014. 18(3): 147-167.

6. Chen, L., G. Ye, W. Zhou, J. Dijkmans, B. Sels, A. Malfliet, and M. Guo, Influence of MgO precursors on mechanically activated forsterite synthesis. Ceramics International, 2015. 41(10, Part A): 1265112657.

7. Saqaei, M., M. Fathi, H. Edris, V. Mortazavi and N. Hosseini, Effects of adding forsterite bioceramic on in vitro activity and antibacterial properties of bioactive glass-forsterite nanocomposite powders. Advanced Powder Technology, 2016. 27(5): 1922-1932.

8. El-Rashidy, A.A., J.A. Roether, L. Harhaus, U. Kneser and A.R. Boccaccini, Regenerating bone with bioactive glass scaffolds: A review of in vivo studies in bone defect models. Acta Biomaterialia, 2017. 62: 1-28.

9. Saidi, R., M. Fathi and H. Salimijazi, Synthesis and characterization of bioactive glass coated forsterite scaffold for tissue engineering applications. Journal of Alloys and Compounds, 2017. 727 : 956-962.

10. Tejeda-Montes, E., A. Klymov, M.R. Nejadnik, M. Alonso, J.C. Rodriguez-Cabello, X.F. Walboomers, and A. Mata, Mineralization and bone regeneration using a bioactive elastin-like recombinamer membrane. Biomaterials, 2014. 35(29): 8339-8347.

11. Chen, Y., S. Chen, N. Kawazoe and G. Chen, Promoted angiogenesis and osteogenesis by dexamethasone-loaded calcium phosphate nanoparticles/collagen composite scaffolds with microgroove networks. Scientific Reports, 2018. 8(1): 14143.

12. Deng, Y., C. Jiang, C. Li, T. Li, M. Peng, J. Wang, and K. Dai, 3D printed scaffolds of calcium silicatedoped $\beta$-TCP synergize with co-cultured endothelial and stromal cells to promote vascularization and bone formation. Scientific Reports, 2017. 7(1): 5588.

13. Samadian, H., S. Farzamfar, A. Vaez, A. Ehterami, A. Bit, M. Alam, A. Goodarzi, G. Darya, and M. Salehi, A tailored polylactic acid/polycaprolactone biodegradable and bioactive 3D porous scaffold containing gelatin nanofibers and Taurine for bone regeneration. Scientific Reports, 2020. 10(1): 13366.

14. Wang, M.M., R.L. Flores, L. Witek, A. Torroni, A. Ibrahim, Z. Wang, H.A. Liss, B.N. Cronstein, C.D. Lopez, S.G. Maliha, and P.G. Coelho, Dipyridamole-loaded 3D-printed bioceramic scaffolds stimulate pediatric bone regeneration in vivo without disruption of craniofacial growth through facial maturity. Scientific Reports, 2019. 9(1): 18439. 
15. Tavangarian, F., A. Fahami, G. Li, M. Kazemi and A. Forghani, Structural characterization and strengthening mechanism of forsterite nanostructured scaffolds synthesized by multistep sintering method. Journal of Materials Science \& Technology, 2018. 34(12): 2263-2270.

16. Sadeghzade, S., R. Emadi, F. Tavangarian and M. Naderi, Fabrication and evaluation of silica-based ceramic scaffolds for hard tissue engineering applications. Materials Science and Engineering: C, 2017. 71: 431-438.

17. Venkatraman, S.K., R. Choudhary, G. Krishnamurithy, H.R.B. Raghavendran, M.R. Murali, T. Kamarul, A. Suresh, J. Abraham, and S. Swamiappan, Biomineralization, mechanical, antibacterial and biological investigation of larnite and rankinite bioceramics. Materials Science and Engineering: C, 2021. 118: 111466.

18. Gao, C., P. Feng, S. Peng and C. Shuai, Carbon nanotube, graphene and boron nitride nanotube reinforced bioactive ceramics for bone repair. Acta Biomaterialia, 2017. 61: 1-20.

19. Choudhary, R., P. Manohar, J. Vecstaudza, M.J. Yáñez-Gascón, H.P. Sánchez, R. Nachimuthu, J. Locs, and S. Swamiappan, Preparation of nanocrystalline forsterite by combustion of different fuels and their comparative in-vitro bioactivity, dissolution behaviour and antibacterial studies. Materials Science and Engineering: C, 2017. 77: 811-822.

20. Abazari, S., A. Shamsipur, H.R. Bakhsheshi-Rad, S. Ramakrishna and F. Berto, Graphene family nanomaterial reinforced magnesium-based matrix composites for biomedical application: A comprehensive review. Metals, 2020. 10(8): 1002.

21. Tjong, S.C., Recent progress in the development and properties of novel metal matrix nanocomposites reinforced with carbon nanotubes and graphene nanosheets. Materials Science and Engineering: R: Reports, 2013. 74(10): 281-350.

22. Abazari, S., A. Shamsipur, H.R. Bakhsheshi-Rad, A.F. Ismail, S. Sharif, M. Razzaghi, S. Ramakrishna, and F. Berto, Carbon nanotubes (CNTs)-Reinforced magnesium-based matrix composites: A comprehensive review. Materials, 2020. 13(19): 4421.

23. Shuai, C., P. Feng, P. Wu, Y. Liu, X. Liu, D. Lai, C. Gao, and S. Peng, A combined nanostructure constructed by graphene and boron nitride nanotubes reinforces ceramic scaffolds. Chemical Engineering Journal, 2017. 313: 487-497.

24. Yi, J., G. Choe, J. Park and J.Y. Lee, Graphene oxide-incorporated hydrogels for biomedical applications. Polymer Journal, 2020. 52(8): 823-837.

25. Hermenean, A., A. Codreanu, H. Herman, C. Balta, M. Rosu, C.V. Mihali, A. Ivan, S. Dinescu, M. Ionita, and $M$. Costache, Chitosan-graphene oxide 3D scaffolds as promising tools for bone regeneration in critical-size mouse calvarial defects. Scientific Reports, 2017. 7(1): 16641.

26. Hone, J., C. Lee, X. Wei and J. Kysar, Measurement of the elastic properties and intrinsic strength of monolayer graphene. Science, 2008. 321(5887): 385-388.

27. Suk, J.W., R.D. Piner, J. An and R.S. Ruoff, Mechanical properties of monolayer graphene oxide. ACS Nano, 2010. 4(11): 6557-6564. 
28. Peng, S., P. Feng, P. Wu, W. Huang, Y. Yang, W. Guo, C. Gao, and C. Shuai, Graphene oxide as an interface phase between polyetheretherketone and hydroxyapatite for tissue engineering scaffolds. Scientific Reports, 2017. 7(1): 46604.

29. Choi, W., I. Lahiri, R. Seelaboyina and Y.S. Kang, Synthesis of graphene and its applications: a review. Critical Reviews in Solid State and Materials Sciences, 2010. 35(1): 52-71.

30. Seyedsalehi, A., L. Daneshmandi, M. Barajaa, J. Riordan and C.T. Laurencin, Fabrication and characterization of mechanically competent 3D printed polycaprolactone-reduced graphene oxide scaffolds. Scientific Reports, 2020. 10(1): 22210.

31. Akhavan, $\mathrm{O}$. and $\mathrm{E}$. Ghaderi, Toxicity of graphene and graphene oxide nanowalls against bacteria. ACS Nano, 2010. 4(10): 5731-5736.

32. Han, W., Z. Wu, Y. Li and Y. Wang, Graphene family nanomaterials (GFNs)-promising materials for antimicrobial coating and film: A review. Chemical Engineering Journal, 2019. 358: 1022-1037.

33. Gilje, S., S. Han, M. Wang, K.L. Wang and R.B. Kaner, A chemical route to graphene for device applications. Nano Letters, 2007. 7(11): 3394-3398.

34. Stanton, A.E., X. Tong and F. Yang, Extracellular matrix type modulates mechanotransduction of stem cells. Acta Biomaterialia, 2019. 96: 310-320.

35. Romeiro, F.C., M.A. Rodrigues, L.A. Silva, A.C. Catto, L.F. da Silva, E. Longo, E. Nossol, and R.C. Lima, rGO-ZnO nanocomposites for high electrocatalytic effect on water oxidation obtained by microwavehydrothermal method. Applied Surface Science, 2017. 423: 743-751.

36. Shuai, C., T. Liu, C. Gao, P. Feng, T. Xiao, K. Yu, and S. Peng, Mechanical and structural characterization of diopside scaffolds reinforced with graphene. Journal of Alloys and Compounds, 2016. 655: 86-92.

37. Bordbar-Khiabani, A., S. Ebrahimi and B. Yarmand, Highly corrosion protection properties of plasma electrolytic oxidized titanium using rGO nanosheets. Applied Surface Science, 2019. 486: 153-165.

38. Fathyunes, L., J. Khalil-Allafi, S.O.R. Sheykholeslami and M. Moosavifar, Biocompatibility assessment of graphene oxide-hydroxyapatite coating applied on $\mathrm{TiO}_{2}$ nanotubes by ultrasoundassisted pulse electrodeposition. Materials Science and Engineering: C, 2018. 87: 10-21.

39. Gao, C., T. Liu, C. Shuai and S. Peng, Enhancement mechanisms of graphene in nano-58S bioactive glass scaffold: mechanical and biological performance. Scientific Reports, 2014. 4: 4712.

40. Roseti, L., V. Parisi, M. Petretta, C. Cavallo, G. Desando, I. Bartolotti, and B. Grigolo, Scaffolds for bone tissue engineering: state of the art and new perspectives. Materials Science and Engineering: $C$, 2017. 78: 1246-1262.

41. Wu, C., Y. Ramaswamy and $\mathrm{H}$. Zreiqat, Porous diopside $\left(\mathrm{CaMgSi}_{2} \mathrm{O}_{6}\right)$ scaffold: a promising bioactive material for bone tissue engineering. Acta Biomaterialia, 2010. 6(6): 2237-2245.

42. Kopp, A., T. Derra, M. Müther, L. Jauer, J.H. Schleifenbaum, M. Voshage, O. Jung, R. Smeets, and N. Kröger, Influence of design and postprocessing parameters on the degradation behavior and 
mechanical properties of additively manufactured magnesium scaffolds. Acta Biomaterialia, 2019. 98: 23-35.

43. Wu, C. and $\mathrm{H}$. Zreiqat, Porous bioactive diopside $\left(\mathrm{CaMgSi}_{2} \mathrm{O}_{6}\right)$ ceramic microspheres for drug delivery. Acta Biomaterialia, 2010. 6(3): 820-829.

44. Shuai, C., B. Wang, S. Bin, S. Peng and C. Gao, Interfacial strengthening by reduced graphene oxide coated with MgO in biodegradable Mg composites. Materials \& Design, 2020: 108612.

45. Zhou, Y., C. Wu and J. Chang, Bioceramics to regulate stem cells and their microenvironment for tissue regeneration. Materials Today, 2019. 24: 41-56.

46. Hoppe, A., N.S. Güldal and A.R. Boccaccini, A review of the biological response to ionic dissolution products from bioactive glasses and glass-ceramics. Biomaterials, 2011. 32(11): 2757-2774.

47. Shuai, C., H. Sun, P. Wu, C. Gao, Y. Yang, W. Guo, D. Yang, F. Xu, P. Feng, and S. Peng, Biosilicate scaffolds for bone regeneration: influence of introducing SrO. RSC Advances, 2017. 7(35): 2174921757.

48. Wei, G., C. Gong, K. Hu, Y. Wang and Y. Zhang, Biomimetic hydroxyapatite on graphene supports for biomedical applications: a review. Nanomaterials, 2019. 9(10): 1435.

49. Wen, T., X. Wu, M. Liu, Z. Xing, X. Wang and A.-W. Xu, Efficient capture of strontium from aqueous solutions using graphene oxide-hydroxyapatite nanocomposites. Dalton Transactions, 2014. 43(20): 7464-7472.

50. Gheitanchi, R., M. Kharaziha and R. Emadi, Sr-doped forsterite nanopowder: Synthesis and biological properties. Ceramics International, 2017. 43(15): 12018-12025.

51. Fabbri, P., L. Valentini, J. Hum, R. Detsch and A.R. Boccaccini, $45 S 5$ Bioglass ${ }^{\circledR}$-derived scaffolds coated with organic-inorganic hybrids containing graphene. Materials Science and Engineering: C, 2013. 33(7): 3592-3600.

52. Munir, K.S., C. Wen and Y. Li, Carbon nanotubes and graphene as nanoreinforcements in metallic biomaterials: a review. Advanced Biosystems, 2019. 3(3): 1800212.

53. Lee, J.H., Y.C. Shin, O.S. Jin, S.H. Kang, Y.-S. Hwang, J.-C. Park, S.W. Hong, and D.-W. Han, Reduced graphene oxide-coated hydroxyapatite composites stimulate spontaneous osteogenic differentiation of human mesenchymal stem cells. Nanoscale, 2015. 7(27): 11642-11651.

54. Shuai, C., W. Guo, P. Wu, W. Yang, S. Hu, Y. Xia, and P. Feng, A graphene oxide-Ag co-dispersing nanosystem: Dual synergistic effects on antibacterial activities and mechanical properties of polymer scaffolds. Chemical Engineering Journal, 2018. 347: 322-333.

55. Hegab, H.M., A. ElMekawy, L. Zou, D. Mulcahy, C.P. Saint and M. Ginic-Markovic, The controversial antibacterial activity of graphene-based materials. Carbon, 2016. 105: 362-376.

56. Li, C., X. Wang, F. Chen, C. Zhang, X. Zhi, K. Wang, and D. Cui, The antifungal activity of graphene oxide-silver nanocomposites. Biomaterials, 2013. 34(15): 3882-3890.

\section{Figures}



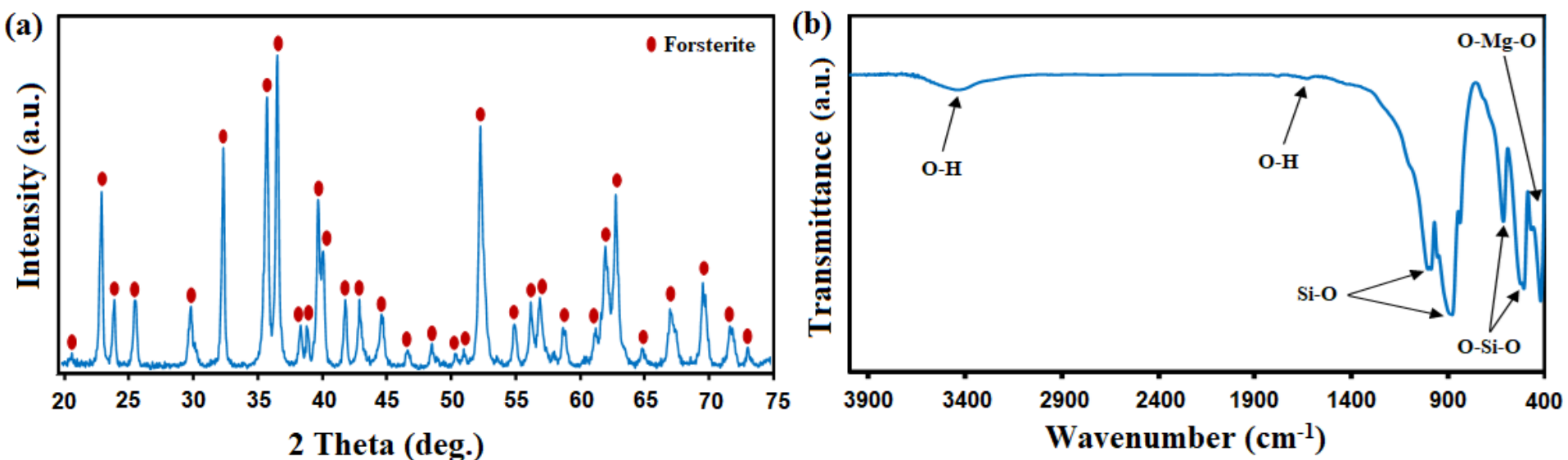

(c)

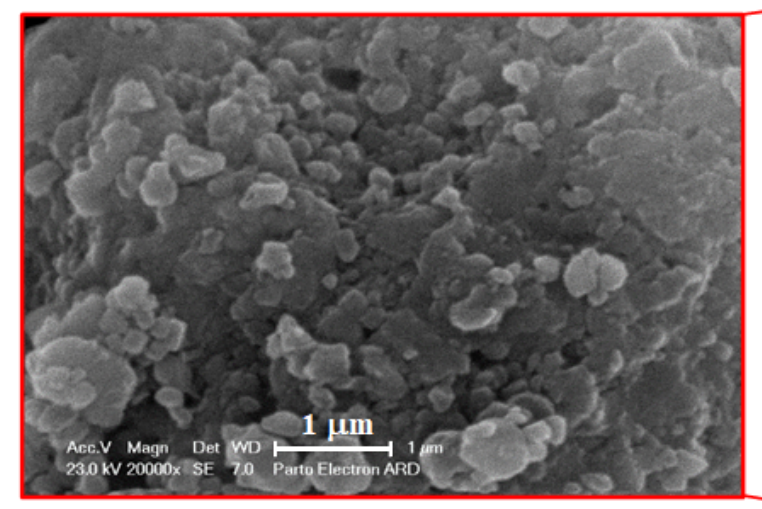

(d)
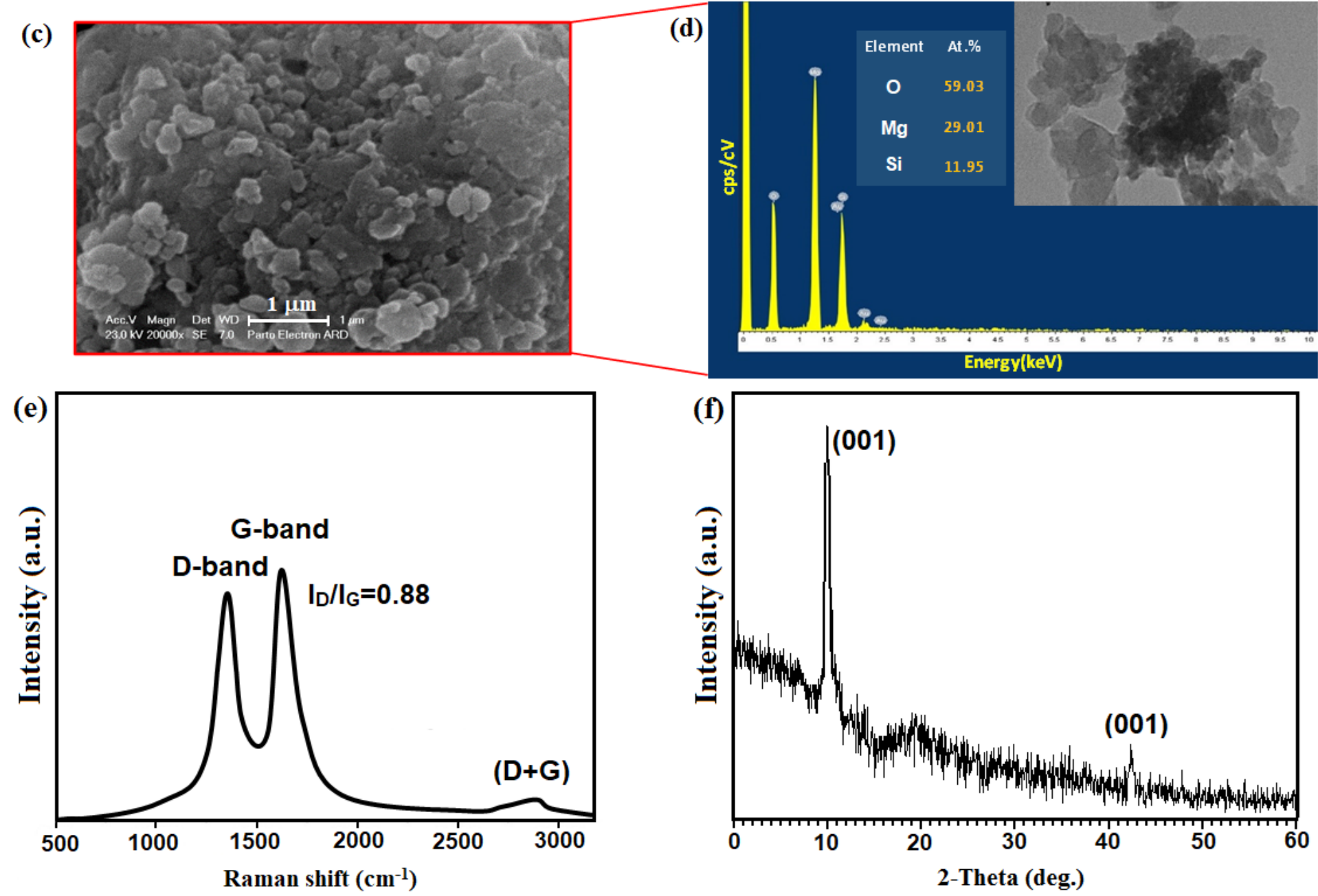

Figure 1

(a) XRD pattern, (b) FTIR absorption spectra (c) SEM image, (d) EDS analysis (in frame is TEM micrograph of forsterite nanopowders and (e) Raman spectra and (f) XRD pattern of GO powder 

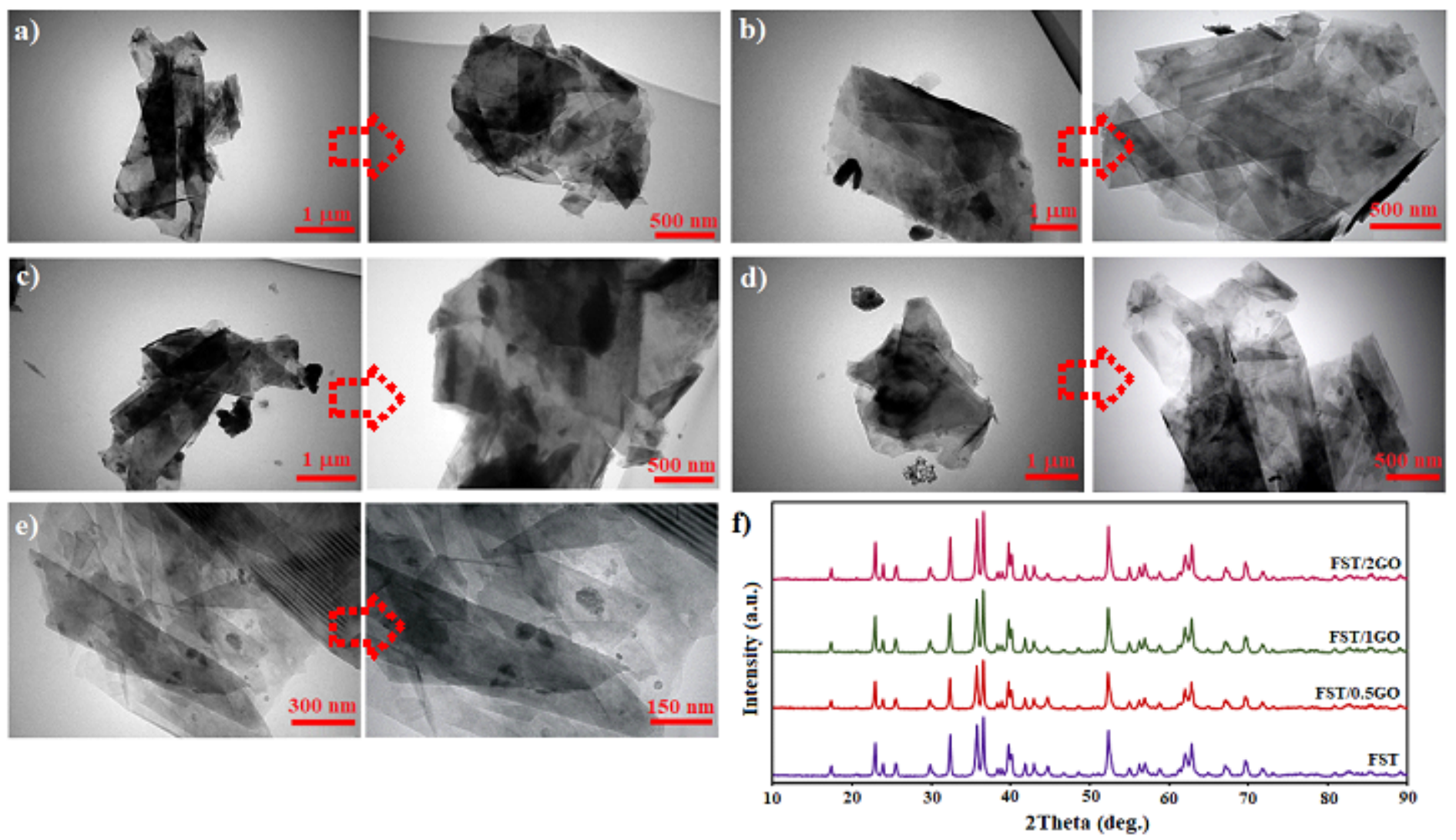

Figure 2

TEM images of (a) GO nanosheets and (b) FST-0.5GO, (c) FST-1GO, and (d,e) FST-2GO and (f) XRD pattern FST-0.5GO nanocomposite powders. 

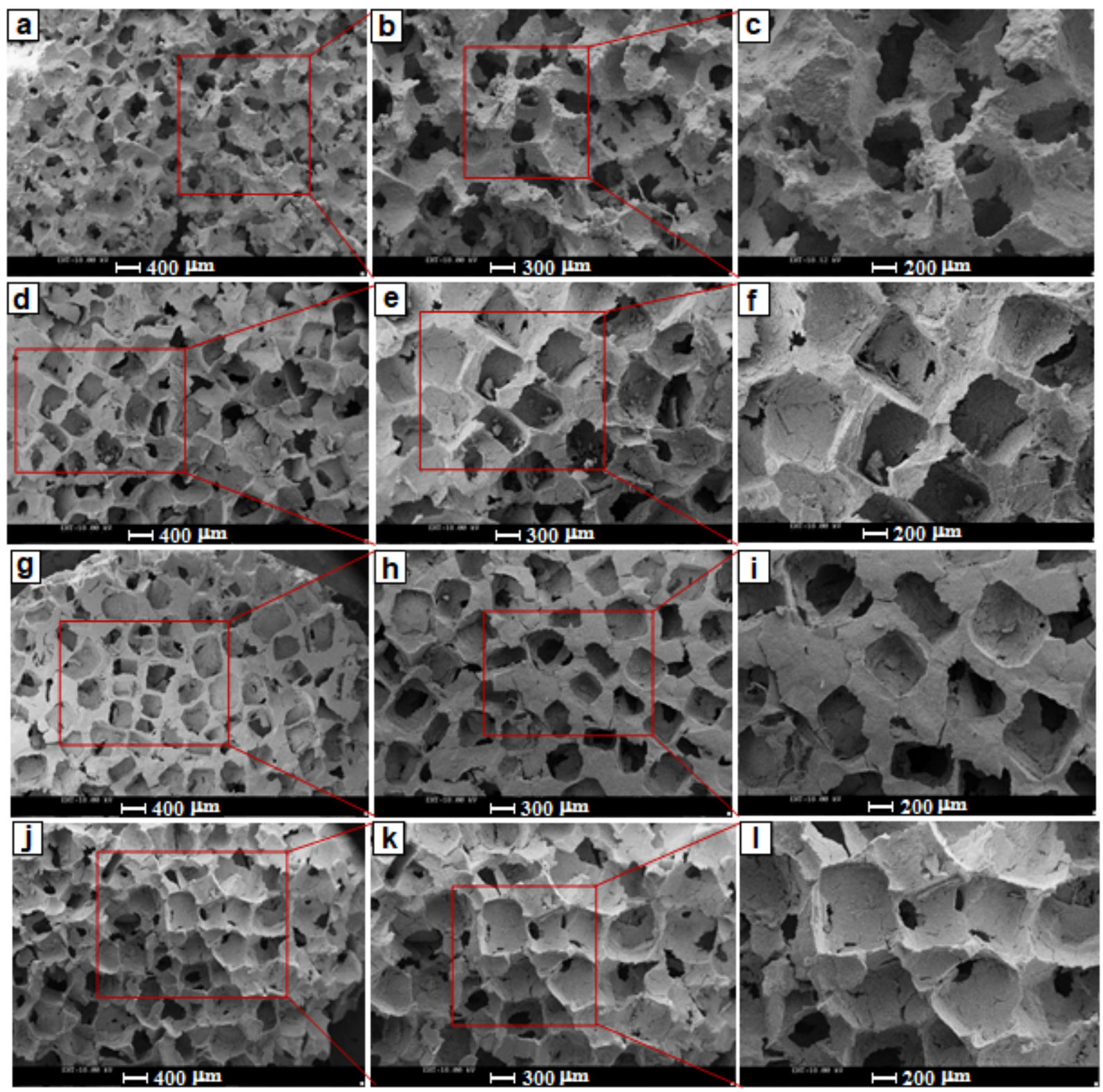

Figure 3

SEM images of (a-c) FST and (d-f) FST-0.5GO, (g-i) FST-1GO, and (j-I) FST-2GO nanocomposite scaffolds. 

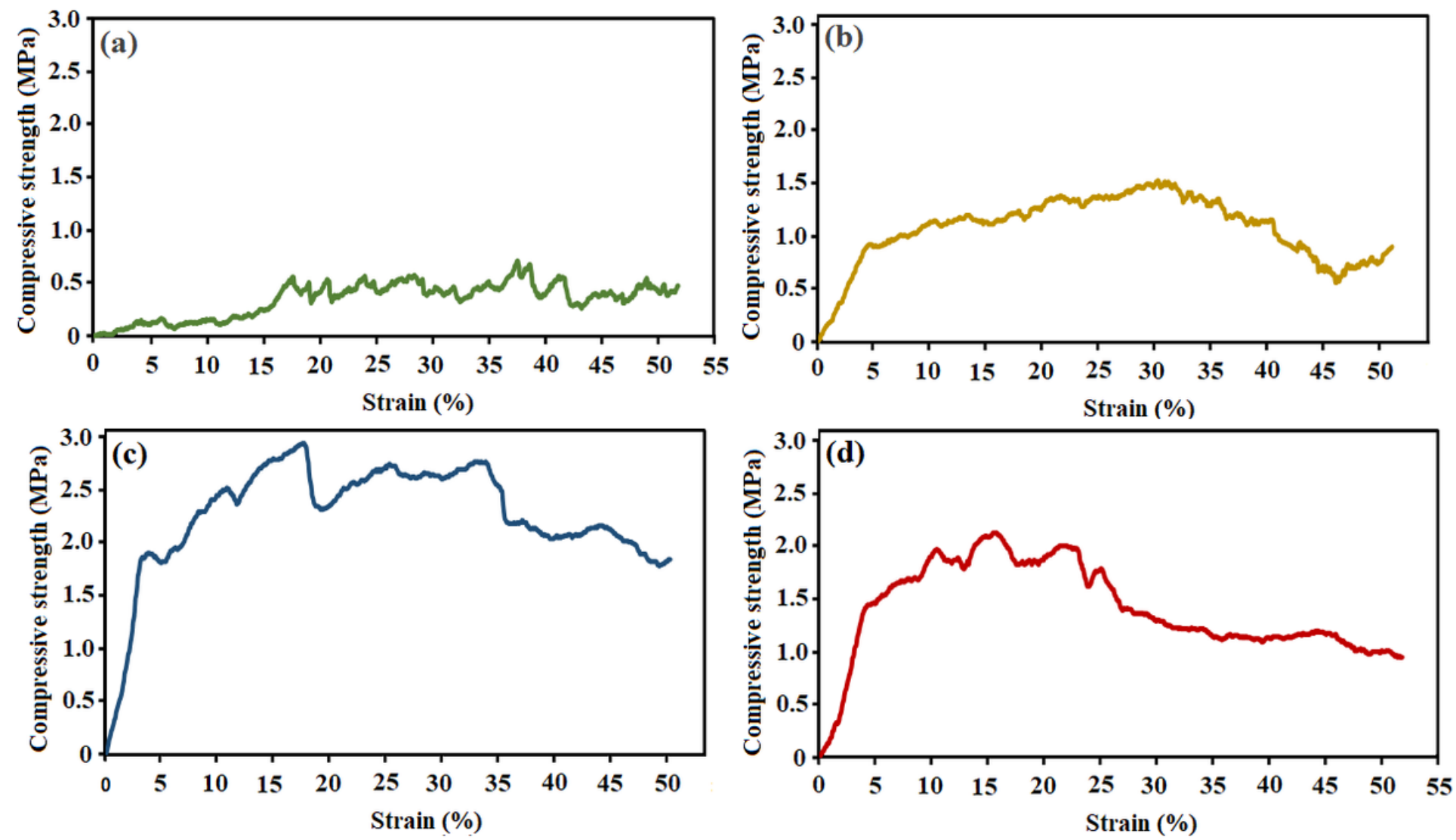

(e)
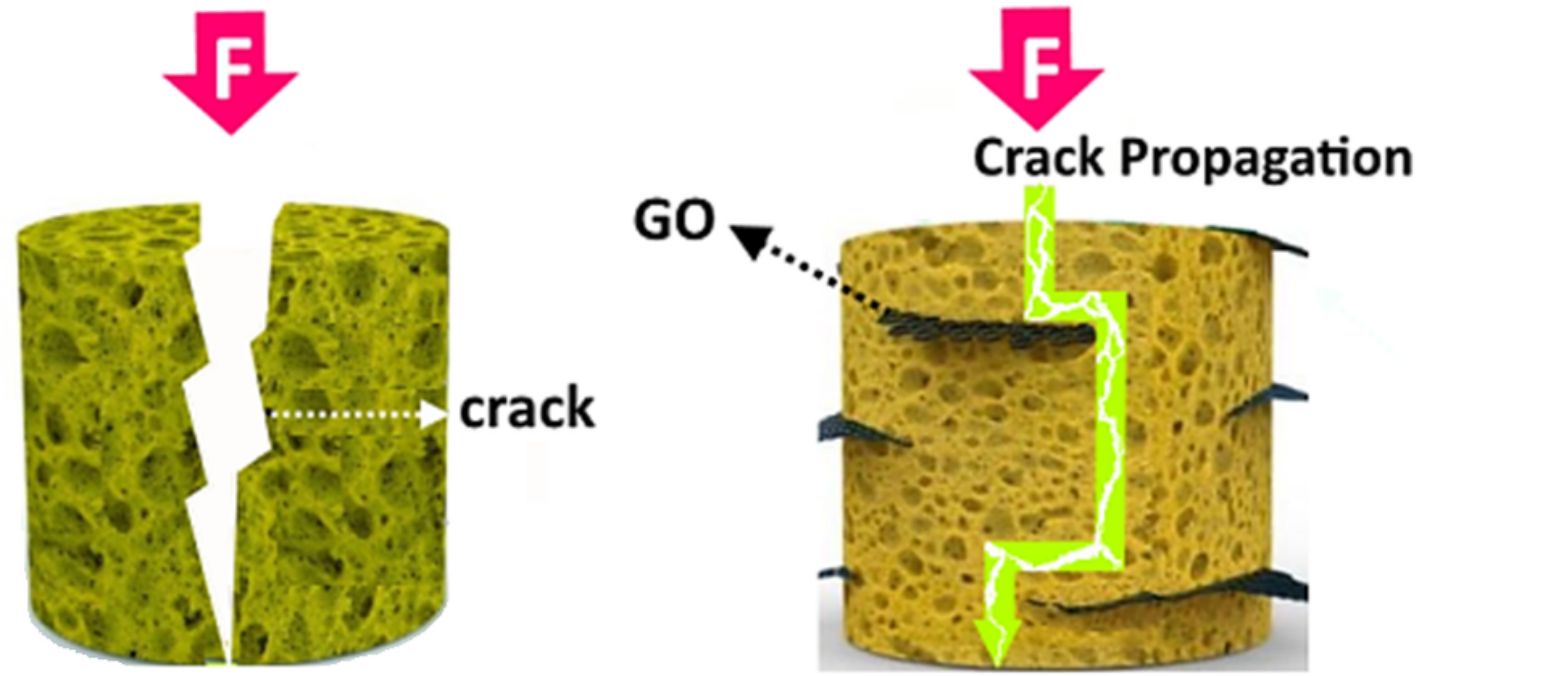

Figure 4

Compressive stress-strain curve of the (a) FST and (b) FST-0.5GO, (c) FST-1GO, and (d) FST-2GO nanocomposite scaffolds and (e) Schematic diagram demonstrate crack deflection mechanisms by graphene in FST-GO nanocomposite scaffolds. 

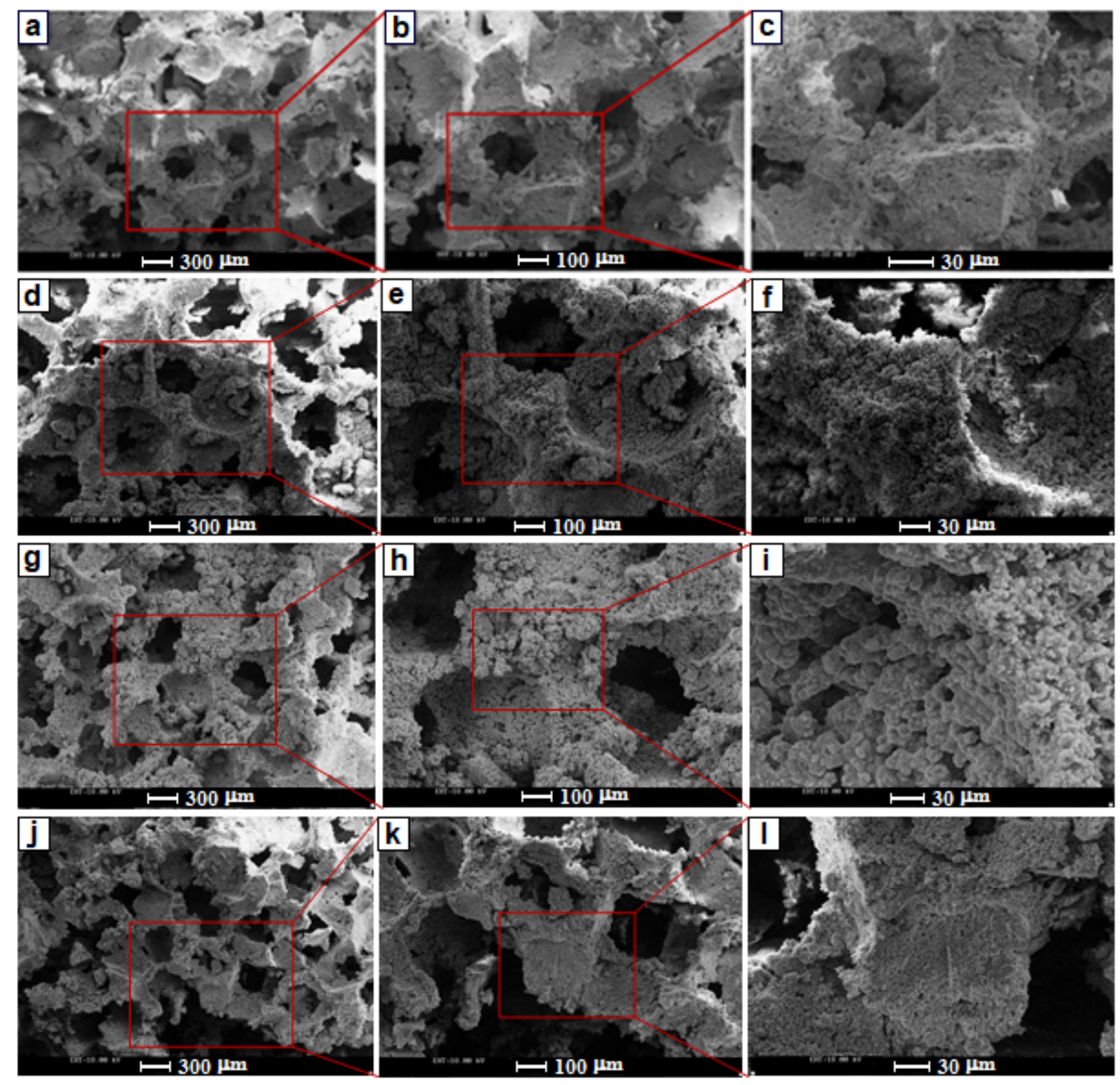

Figure 5

SEM images of (a-c) FST and (d-f) FST-0.5GO, (g-i) FST-1GO, and (j-1) FST-2GO nanocomposite scaffolds after immersion in the SBF solution for 28 days 
a)
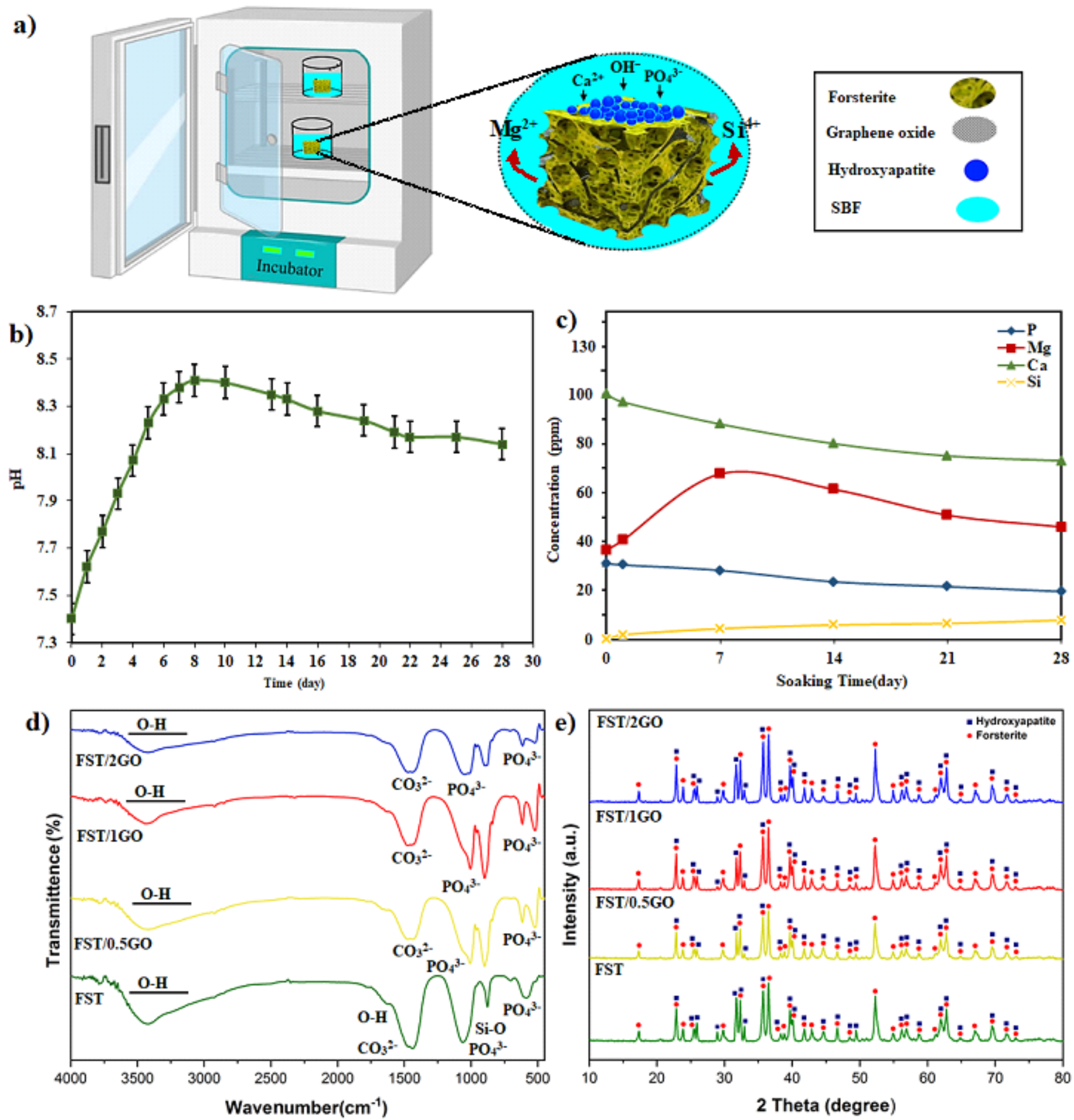

\section{Figure 6}

(a) Schematic representation of the mechanism of apatite formation on the surface of FST-GO scaffolds in the SBF solution and (b) pH changes in the SBF solution, and (c) and ion concentrations changes, after soaking the FST-GO nanocomposite scaffolds and d) FTIR absorption spectra and e) XRD pattern of FSTGO nanocomposite scaffolds after immersion in the SBF solution 

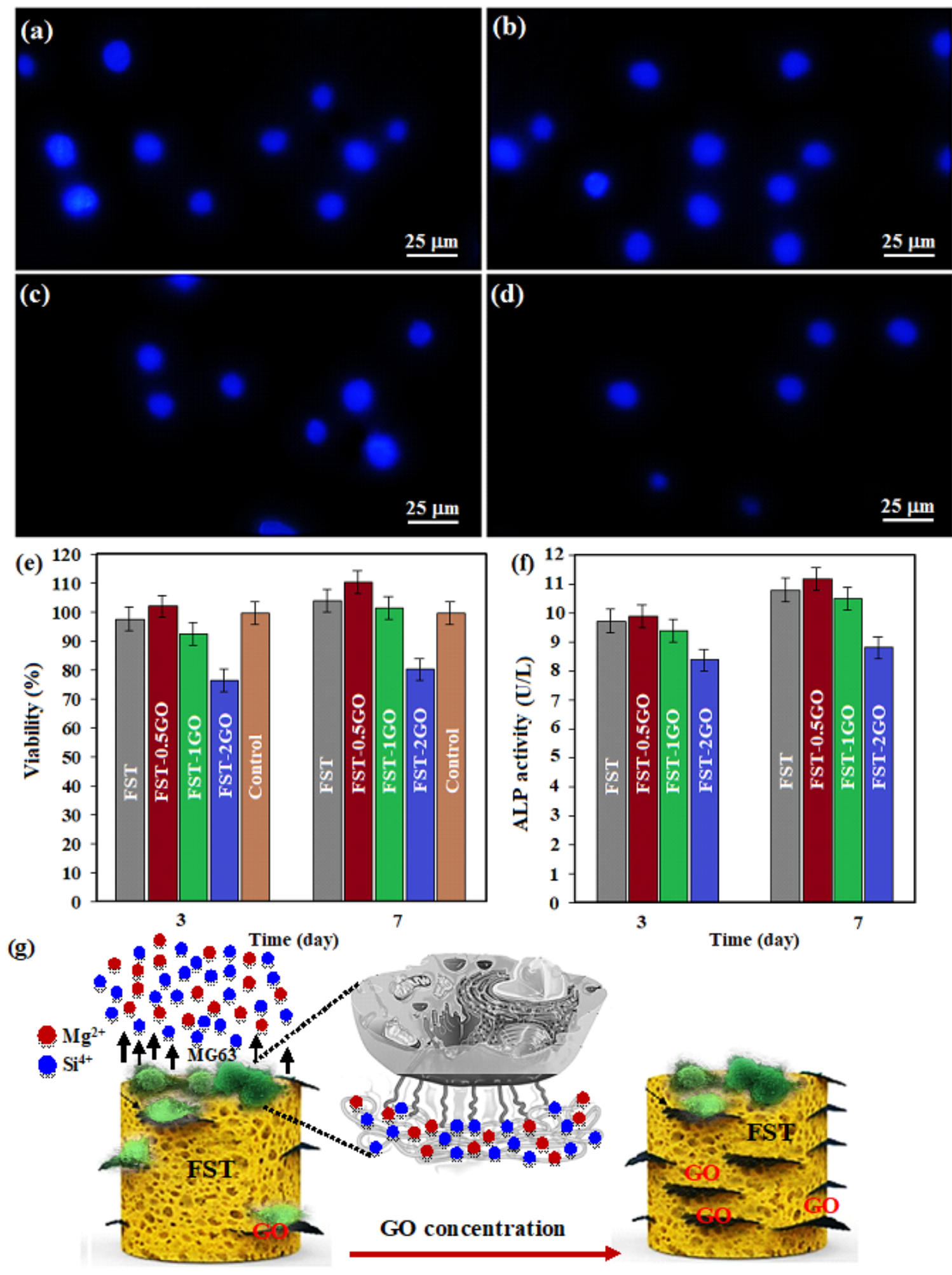

\section{Figure 7}

DAPI staining of MG63 cells cultured on a forsterite scaffold (a) and forsterite scaffolds with $0.5 \mathrm{wt} . \%$ (b), $1 \mathrm{wt} . \%$ (c), and $2 \mathrm{wt. \%}$ (d) GO. (e) cell viability, and (f) ALP activity of MG63 cells cultured for various times on forsterite/GO scaffolds $\left({ }^{*} \mathrm{p}<0.05\right)$ and $(\mathrm{g})$ Schematic demonstration of the interactions between the MG63 osteoblast cells and forsterite/GO scaffolds 


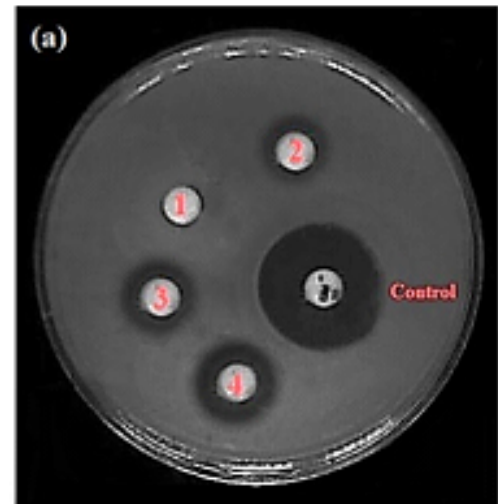

(c)

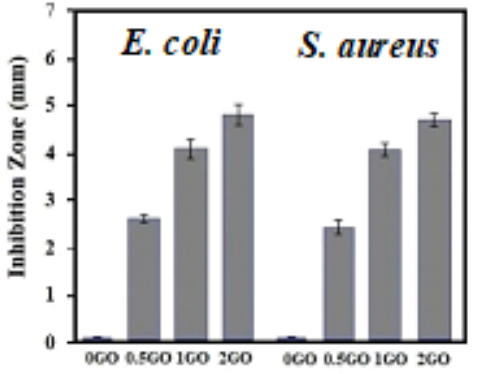

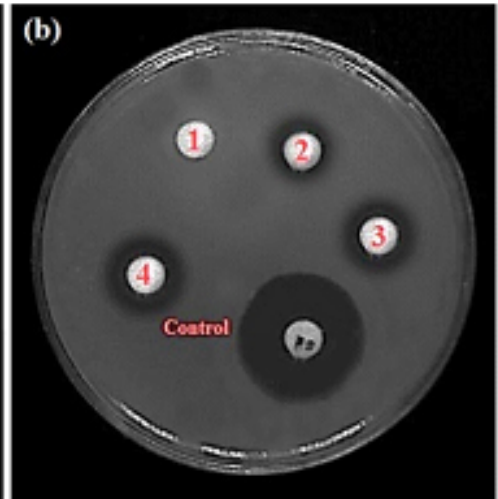

(d)

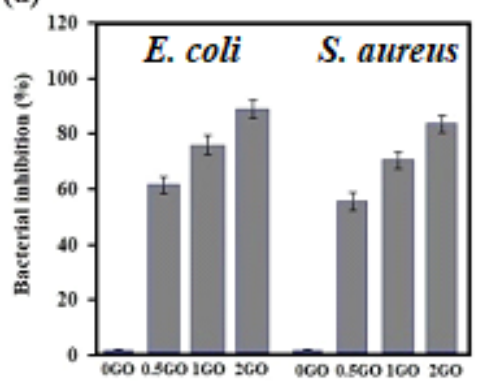

(e)
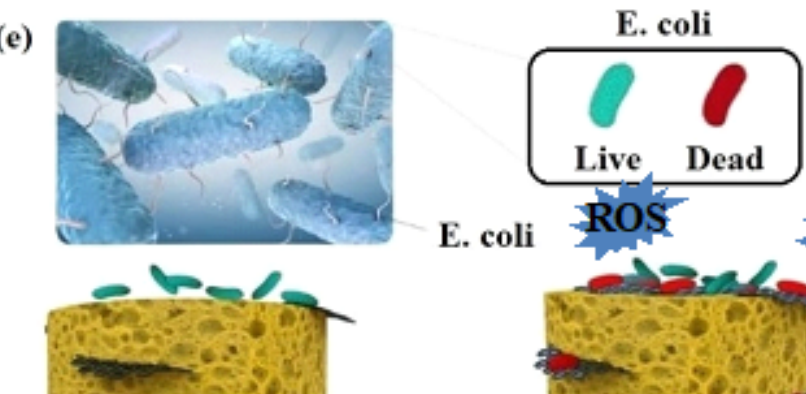

FST/GO
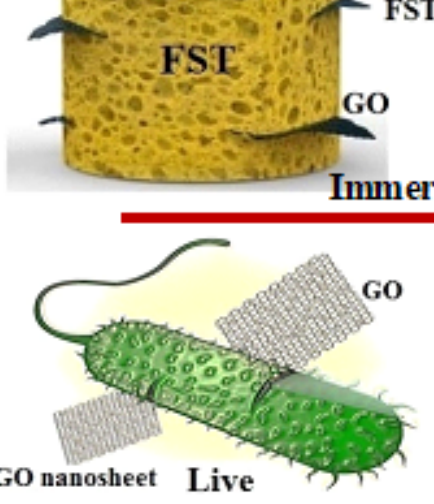

rsion time

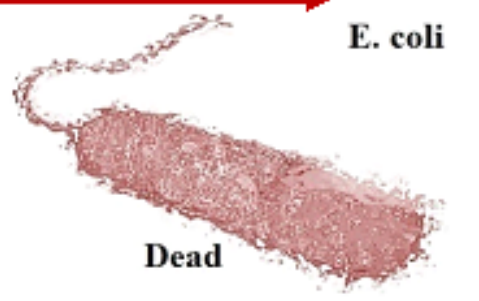

\section{Figure 8}

Images of inhibition zones of the forsterite and forsterite/GO scaffolds after $24 \mathrm{~h}$ against (a) Grampositive (S. aureus) and (b) Gram-negative (E. coli) and (c) values of growth inhibition zones and (d) and percentage of bacterial inhibition against $S$. aureus and E. coli bacteria $\left({ }^{*} p<0.05\right)$ and (e) Schematic of the antimicrobial mechanism of forsterite scaffolds encapsulated with GO.

\section{Supplementary Files}

This is a list of supplementary files associated with this preprint. Click to download.

- Supplementarylnformation.docx

- GraphicalAbstract.png

- Scheme01.png 